\title{
Olfactory Deterioration in Mild Cognitive Impairment
}

\author{
Katerina Touliou* and Evangelos Bekiaris \\ Centre for Research and Technology Hellas, Greece
}

*Corresponding author: Katerina Touliou, Centre for Research and Technology Hellas (CERTH)/ Hellenic Institute of Transport (HIT), 6th km Charilaou-Thermis, 57 001, Thessaloniki, Greece

\begin{tabular}{|c|c|}
\hline ARTICLE INFO & ABSTRACT \\
\hline Received: 㗀 January 31, 2020 & Olfaction is important for many everyday activities, ranging from feeding to detecting \\
\hline Published: 蔧 February 06, 2020 & $\begin{array}{l}\text { dangerous situations. It is the main reason older adults complain about loss of flavor in } \\
\text { food. Olfactory deterioration is common in older individuals and has been associated }\end{array}$ \\
\hline $\begin{array}{l}\text { Citation: Katerina Touliou, Evangelos } \\
\text { Bekiaris. Olfactory Deterioration in Mild } \\
\text { Cognitive Impairment. Biomed J Sci \& Tech } \\
\text { Res 25(3)-2020. BJSTR. MS.ID.004195. }\end{array}$ & $\begin{array}{l}\text { with early onset of several neurodegenerative diseases. Olfaction deteriorates from } \\
\text { normosmic, which is normal smell ability to hyposmia (decreased ability) and anosmia } \\
\text { (complete loss) and is often quantified in threshold, discrimination and identification } \\
\text { scores through standardized smell tests. Identifying the true cause of smell decline is } \\
\text { often difficult and problematic, because there are many factors that affect the ability } \\
\text { to smell like age, gender, smoking, genetic predisposition, head injuries and sinonasal }\end{array}$ \\
\hline $\begin{array}{l}\text { Abbreviations: MCI: Mild Cognitive } \\
\text { Impairment, aMCI: amnesic Mild Cognitive } \\
\text { Impairment, UPSIT: Pennsylvania Smell } \\
\text { Identification Test, VAS: Visual Analogue } \\
\text { Scale }\end{array}$ & $\begin{array}{l}\text { diseases. Several studies have supported that the risk for MCI patients to progress to } \\
\text { Alzheimer's disease is } 4 \text { times greater than other older persons for older adults with } \\
\text { olfactory deficits. Finally, as the underlying pathology and mechanisms need further } \\
\text { research and clarification, focusing on different MCI subtypes might prove useful in } \\
\text { revealing these mechanisms. }\end{array}$ \\
\hline
\end{tabular}

Keywords: Olfactory; Smell; Cognitive Impairment; MCI

\section{Mini Review}

Olfaction is important for many everyday activities, ranging from feeding to detecting dangerous situations and its loss affects even more facets of everyday living [1]. It is the main reason older adults complain about loss of flavor in food. Olfactory deterioration is common in older individuals and has been associated with early onset of several neurodegenerative diseases (e.g. Alzheimer's disease, Parkinson's, Huntington's, Lew Body, etc.) [2]. Smell loss has been found in $80 \%$ of individuals over 80 years old [3] and it has been associated with higher mortality rates in the older population [4] and more with men than women [5]. Cognitive and, specifically, episodic memory decline seems to be affected in people with impaired smell identification and for this reason olfactory impairment is often investigated as a predictor of early cognitive impairment, as it is the case for Mild Cognitive Impairment (MCI) [6]. Thus, it is considered as an early-stage and progression clinical marker.

\section{Measuring the Olfactory Ability}

Olfaction deteriorates from normosmic, which is normal smell ability to hyposmia (decreased ability) and anosmia (complete loss) and is often quantified in threshold, discrimination and identification scores estimated through standardized smell tests. In threshold tests, participants must detect the smell across different concentrations. The threshold is set when the odour is detected in the lowest concentration. Discrimination is related to the differentiation between smells. The participant must identify the smell among other ones. Two of the most well-known and widely administered psychophysiological smell tests are the Pennsylvania Smell identification Test (UPSIT) [7] and the Sniffin' Sticks Test [8]. Both tests have been validated in different languages and countries and age and gender stratified normative values exist. Certain cultural adaptations have been applied to ensure the face validity of the tests is not affected. The Visual Analogue Scale (VAS) has been used to assess olfactory deficit and is significantly correlated to UPSIT for Parkinson's disease [9], making it an easy and quick instrument to investigate olfactory deterioration. Further research is necessary to ensure reliability and replicability of the findings. Identifying the true cause of smell decline is often difficult and problematic because there are many factors that affect the ability to smell like age, gender, smoking, genetic predisposition, head injuries and sinonasal diseases [10]. Further research on the exact role and effect of these factors on olfactory decline will shed more 
light on the actual process of deterioration in neurodegenerative disorders and early cognitive impairment.

\section{Olfactory Decline in MCI}

Mild Cognitive Impairment (MCI) is a term coined over 40 years ago and still pertains literature and research, perplexing researchers and health professionals alike and places emphasis on early identification of cognitive deficits. Initially, the term was used to describe slight memory impairment that did not meet dementia criteria, but over the years many terms were used to define and describe MCI. Current research focuses on the MCI subtypes (e.g. amnesic and non-amnesic) and to other symptoms, apart to the ones related to memory decline. It is also clear that not all MCI patients will progress to dementia. Neuroanatomic and neurophysiological changes in the primary olfactory cortex and system in general result in decline in the ability to identify smells and those are often large in MCI patients [11-13], as well as the changes in the hippocampus and the entorhinal cortex [14]. Several studies have demonstrated that olfactory deterioration occurs before the onset of dementia and can distinguish MCI patients from the control group and, thus, have a predictive power on who will progress to dementia or not [1518]. Lack of homogeneity in MCI terminology, diagnosis methods, and olfactory tests applied as well as differences in the conduction methodologies and procedures does not allow for consistent and easily generalizable inferences [13]. Targeting research on different MCI subtypes -with inherent clinical heterogeneity- could lead to identification of prodromal dementia and distinguish it from healthy aging changes before it happens. For example, memory loss is the predominant characteristic of amnesic MCI (aMCI) with $10 \%-15 \%$ of patients later progressing to Alzheimer's disease [19]. Non-amnesic patients (naMCI) will most probably progress to Lew Body or vascular dementia [20]. Several studies have supported that the risk for MCI patients to progress to Alzheimer's disease is 4 times greater than for other older persons, when olfactory deterioration is present during baseline assessment [21,22]. Based on the meta-analysis conducted by Rahayel and colleagues (2012), the combination of imaging biomarkers, neuropsychological and clinical assessment and smell identification tests could be useful and effective in order to detect Alzheimer's disease and to predict the transition from MCI to Alzheimer's disease [23].

\section{Conclusion}

This mini review was conducted focusing on olfactory impairment measuring instruments and the relation between olfactory decline and MCI. Although smell diminishes early in older individuals with diverse types of neurodegenerative diseases, the reasons are still unclear and not known. It has been hypothesized that disruptions on the primordial neuropathological substrate might be related to decline in the ability to detect, distinguish and identify smells $[9,10]$. As the olfactory dysfunction can appear earlier in non-MCI persons, this dysfunction can be a 'messenger' of preclinical cognitive decline and neurodegenerative disease. Hence, other clinical, neuroimaging or even self-reported complaints can act as a proactive strategy. Finally, as the underlying pathology and mechanisms need further research and clarification, focusing on different MCI subtypes might prove useful in revealing these mechanisms.

\section{Acknowledgment}

This mini review was conducted as part of the fulfillment of the PhD Thesis of Ms. Katerina Touliou in collaboration with the Laboratory of Medical Informatics of the Medical School of the Aristotle University of Thessaloniki.

\section{Conflict of interest}

The authors declare that they have no conflict of interest.

\section{References}

1. Hummel T, Landis BN, Hüttenbrik KB (2011) Smell and taste disorders. GMS Curr Top Otorhinolaryngol Head Neck Surg 10: Doc04

2. Gallarda BW, Lledo PM (2012) Adult neurogenesis in the olfactory system and neurodegenerative disease. Curr Mol Med 12(10): 12531260.

3. Doty RL, Kamath V (2014) The influences of age on olfaction: A review. Front Psychol 5: 20.

4. Gopinath B, Sue CM, Kifley A, Mitchell P (2012) The association between olfactory impairment and total mortality in older adults. J Gerontol A Biol Sci Med Sci 67(2): 204-209.

5. Choudhury ES, Moberg P, Doty RL (2003) Influences of age and sex on a microencapsulated odor memory test. Chem Senses 28(9): 799-805.

6. Alves J, Petrosyan A, Magalhaes R (2014) Olfactory dysfunction in dementia. World J Clin Cases 2: 661-667.

7. Doty RL, Deems DA, Stellar S (1988) Olfactory dysfunction in parkinsonism: a general deficit unrelated to neurologic signs, disease stage, or disease duration. Neurology 38: 1237-1244.

8. Kobal G, Hummel T, Sekinger B, Baez S, Roscher S, et al. (1996) "Sniffin'sticks": screening of olfactory performance. Rhinology 34(4): 222-226.

9. Marin C, Vilas D, Langdon C, Alobid I, López Chacón, et al. (2018). Olfactory dysfunction in neurodegenerative diseases. Current allergy and asthma reports 18(8): 42 .

10. Doty RL (2017) Olfactory dysfunction in neurodegenerative diseases: is there a common pathological substrate? Lancet Neurol 16: 478-88.

11. Davies DC, Brooks JW, Lewis DA (1993) Axonal loss from the olfactory tracts in Alzheimer's disease. Neurobiol Aging 14: 353-357.

12. Vasavada MM, Wang J, Eslinger PJ (2015) Olfactory cortex degeneration in Alzheimer's disease and mild cognitive impairment. J Alzheimers Dis 45(3): 947-958.

13. Roalf DR, Moberg MJ, Turetsky BI, Brennan L, Kabadi S, et al. (2017) A quantitative meta-analysis of olfactory dysfunction in mild cognitive impairment. Journal of Neurology, Neurosurgery \& Psychiatry 88(3): 226-232.

14. Devanand DP, Pradhaban G, Liu X, Tabert MH, De Leon MJ, et al. (2007) Hippocampal and entorhinal atrophy in mild cognitive impairment: prediction of Alzheimer disease. Neurology 68(11): 828-36.

15. Vyhnalek M, Magerova H, Andel R (2015) Olfactory identification in amnestic and non-amnestic mild cognitive impairment and its neuropsychological correlates. J Neurol Sci 349: 179-84. 
16. Roberts RO, Christianson TJ, Kremers WK, Knopman DS, Petersen RC, et al. (2016) Association between olfactory dysfunction and amnestic mild cognitive impairment and Alzheimer disease dementia. JAMA Neurol 73: 93-101.

17. Conti MZ, Vicini Chilovi B, Riva M (2013) Odour identification deficit predicts clinical conversion from mild cognitive impairment to dementia due to Alzheimer's disease. Arch Clin Neuropsychol 28(5): 391-399.

18. Sun GH, Raji CA, Mac Eachern MP (2012) Olfactory identification testing as a predictor of the development of Alzeimer's dementia: a systematic review. Laryngoscope 122: 1455-1462.

19. Grundman M, Petersen RC, Ferris SH, Thomas RG, Aisen PS, et al. (2004) Mild cognitive impairment can be distinguished from Alzheimer disease and normal aging for clinical trials. Arch Neurol 61: 59-66.

\section{ISSN: 2574-1241}

DOI: 10.26717/BJSTR.2020.25.004195

Katerina Touliou. Biomed J Sci \& Tech Res

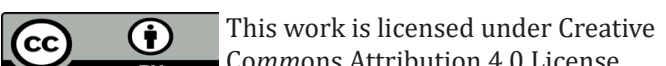

Submission Link: https://biomedres.us/submit-manuscript.php
20. Tabert MH, Manly JJ, Liu X, Pelton GH, Rosenblum S, et al. (2006) Neuropsychological prediction of conversion to Alzheimer disease in patients with mild cognitive impairment. Arch Gen Psychiatry 63(8): 916-924.

21. Woodward MR, Amrutkar CV, Ahah HC, Benedict RH, Rajakrishnan S, et al. (2017) Validation of olfactory deficit as a biomarker of Alzheimer disease. Neurol Clin Pract 7(1): 5-14.

22. Devanand DP, Lee S, Manly J (2015) Olfactory deficits predict cognitive decline and Alzheimer dementia in an urban community. Neurology 84(2): 182-189.

23. Rahayel S, Frasnelli J, Joubert S (2012) The effect of Alzheimer's disease and Parkinson's disease on olfaction: a meta-analysis. Behav Brain Res 231(1): 60-74.

$\begin{array}{ll}\text { BIOMEDICAL } & \text { Assets of Publishing with us } \\ \text { RESEARCHES } & \text { - Global archiving of articles } \\ \text { - Immediate, unrestricted online access }\end{array}$

